\title{
The Effect of Machined Surface Conditioning on the Coating Interface of High Velocity Oxygen Fuel (HVOF) Sprayed Coating
}

\author{
Meik Tilger ${ }^{1 *}$, Dirk Biermann ${ }^{1}{ }^{\circledR}$, Mohamed Abdulgader ${ }^{2}$ and Wolfgang Tillmann ${ }^{2}$ \\ 1 Institute of Machining Technology, Technical University Dortmund, 44227 Dortmund, Germany \\ 2 Institute of Materials Engineering, Technical University Dortmund, 44227 Dortmund, Germany \\ * Correspondence: meik.tilger@tu-dortmund.de; Tel.: +49-231-755-5274
}

Received: 28 June 2019; Accepted: 30 August 2019; Published: 3 September 2019

\begin{abstract}
Roughening the substrate surface is essential for thermal sprayed coatings. In this regard, sandblasting has established itself as an easy to use surface conditioning procedure. The quality of the obtained roughness depends on the conditions of the sandblasting material, adjusted parameters, and the kind of the process execution (manual or mechanical). These preconditions limit the reproducibility of the roughness obtained. Sandblasting causes residual compressive stress and may also lead to the inclusion of sand particles and notches in the roughened surface, which affects the interfacial properties of the coating, as well as the flexural strength of the coated parts. The hardness of the roughened surface plays, thereby, an important role. However, in order to reliably avoid these effects, microfinishing can be used as an alternative to generate a homogenous roughened substrate surface, control the induced residual stresses, and increase the reproducibility. In addition, the roughened surface pattern can be produced during the chip forming process of the to-be-coated parts. The utilization of the appropriate combination of machining processes and parameters should lead to the required surface pattern and thus to an enhanced coating adhesion and flexural strength of the coated part. The induced residual stresses and the quality of the obtained surface roughness have a significant influence on the coating adhesion and the lifespan of the coated parts. This paper aims to analyze, as a first step, the effect of the turning and microfinishing on the surface conditioning of the bearing steel 100Cr6 (AISI 52100). The investigation concludes by comparing the microfinished with the sandblasted surfaces with regard to the interface to and the adhesion of the WC-Co high velocity oxygen fuel (HVOF) sprayed coatings on them. Surface conditioning plays a decisive role by the induced residual stresses and the elimination of adhesion defects.
\end{abstract}

Keywords: surface integrity; machining; turning; honing; coating; topography

\section{Introduction}

Technical progress demands more capable surfaces for a lot of applications with highly-loaded components that can withstand a variety of tribological, mechanical, and chemical stresses [1,2]. In order to increase the service life time of such components, there are a number of technological approaches, e.g., microfinished guide pads for BTA deep hole drills (BTA: Boring and Trepanning Association) [3,4]. One possibility to reduce the wear of tribological functional surfaces is the application of so-called wear protection layers by coating processes [5-7].

Thermally sprayed coatings are characterized by high resistance to wear, cavitation, corrosion, and thermal loads. In real applications, the coated components are often subjected to stress collective that includes, in addition, dynamic stresses. For this reason, the dynamic strength must be considered when designing the coating of mechanical parts and components. The collective stresses have been 
extensively studied for uncoated parts for different materials and components. In contrast, the resistance to dynamic loads combined with an increased service life of a coating system has not yet been thoroughly investigated. The reason for this is that the dynamic behavior of a coated part and component is influenced by diverse factors that affect the bonding strength, crack formation, and propagation. Furthermore, the bonding defects (notches and contaminations caused by sandblasting) at the coating interface, cracks, and pores as microscopic and macroscopic defects in the obtained coatings would inevitably lead to the crack formation and propagation in the coated components as a result of the dynamic stresses [8-11]. The roughening of the substrate surface is an essential prerequisite to ensure a sufficient mechanical bonding of the impacted particles with the substrate surface, as shown in Figure 1. This fact makes the generation of bonding defects in particular notches, and thus the deterioration of dynamic strength, unavoidable by using sandblasting.

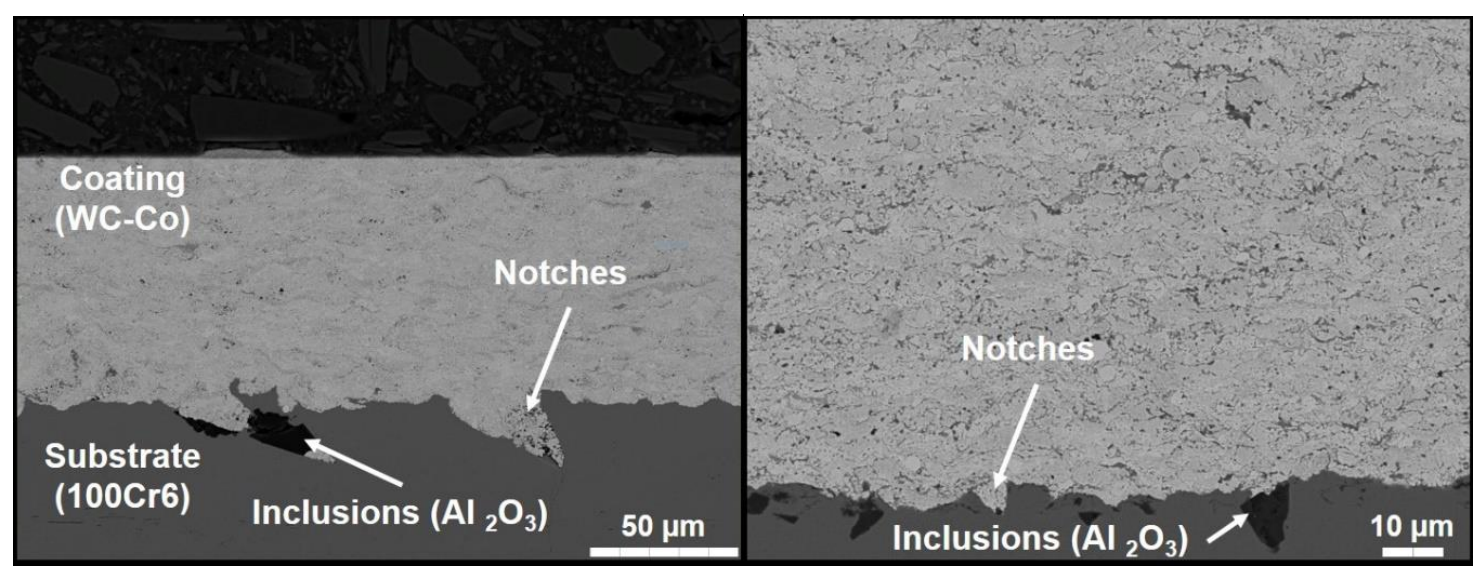

Figure 1. Interfacial bonding of sandblasted substrate surface.

The new development in the high velocity oxygen fuel (HVOF) spraying technique enables the use of fine powders as a feedstock and therefore the production of coatings with lower porosities, lower roughness, and higher adhesive strength [12,13]. This development may enhance, through the reduction of the microstructure defects, the dynamic behavior of the obtained coatings. However, the number, size, and distribution of the remaining defects, as well as the generated undesirable notches and inclusions, are still critical for the dynamic behavior of the obtained coating system $[9,10]$. Moreover, a number of investigations have been done in thermal spraying in order to determine the effect of the residual stresses on the behavior of the obtained coatings [14-18]. The residual stresses during thermal spraying arise from three basic mechanisms: The alternating heat input during repeated passes of the spray flame, the impact of the particles, and the quenching of the spray particles on impact [14,19]. Sartwell et al. [20] found that the compressive stresses reveal an improvement in the service life of the components. In general, the resulting residual stresses influence the mechanical properties of the sprayed coatings and can thus lead to a reduction in coating adhesion, dynamic strength, and wear resistance [21-23]. The induced residual stresses, and thus their effect, however, vary depending on the hardness and thermophysical properties of the substrate material used. To study the effects of all these factors on the coating adhesion and dynamic behavior, a substrate material, with a hardness that can be adjusted over a wide range, is needed. The bearing steel $100 \mathrm{Cr} 6$ is, therefore, the most suitable material for the intended investigations.

The following investigations are part of a funded project with the overall objective to improve the fatigue strength of dynamic loaded workpieces. Therefore, a part of this funded project includes investigations on machining surface conditioning and bonding tests for the WC-12Co HVOF coating, which are the subjects of this paper. The main objective of surface conditioning is to improve the coating adhesion by suitable machining processes of the substrate surface. With regard to the surface integrity influenced by the machining, the residual stress on the machined surface is analyzed, in addition to 
the surface topography. These are not directly related to coating adhesion, but are part of the surface integrity analyses and the overall research project to increase the dynamic strength of HVOF-coated components. Since the overall aim is to improve the dynamic strength, rotational bending tests should be carried out finally. Therefore, the workpiece shape is standardized by DIN 50113.

Furthermore, in order to meet the objective of this study, the substrate surface was prepared with turning in combination with two different strategies of microfinishing. In comparison, a typically sandblasted substrate surface is additionally considered. The microfinishing can be used to roughen the substrate surface by creating a plateau patterned surface which, in comparison to sandblasting, does not lead to the adhesion defects [7]. To prepare the substrate surface of hardened 100Cr6 (AISI 52100) steel for an HVOF coating, two roughness profile types were machined by means of microfinishing an initially turned surface. The overall objective in this study is to improve the coating interface and reduce the adhesion defects by a combination of turning and microfinishing. Therefore, the selection of suitable microfinishing parameters is in charge to produce the final substrate surface and thus affect the surface integrity.

Microfinishing, also known as superfinishing or briefly called finishing, precisely describes the process of short-stroke honing which is standardized according to DIN 8589-14 [24]. As the name indicates, microfinishing is generally the last process along the machining process chain. It is mainly used to improve the tribological contact situation without changing the shape by influencing the surface topography and, thereby, its microscopic topography [25]. The tools used can be solid stones or flexible microfinishing belts or films. Both are built out of bonding material and abrasive grains. Typical grain types are diamond (D), corundum $\left(\mathrm{Al}_{2} \mathrm{O}_{3}\right)$, and silicon carbide $(\mathrm{SiC})$, with grain sizes between $d_{K}=1$ and $125 \mu \mathrm{m}[7,26]$.

Microfinishing is a honing process and the kinematics are similar and thus characterized by a rotation of the workpiece and a superimposed orthogonal oscillation of the tool. Generally, the oscillation frequency during microfinishing can be up to $f_{O S}=21 \mathrm{~Hz}$, and a maximum amplitude up to $A=3 \mathrm{~mm}$ [25]. This is equivalent to a width of oscillation of $l_{O s}=6 \mathrm{~mm}$. Due to this short stroke width, microfinishing is also called short-stroke honing. The process kinematics of workpiece rotation and tool oscillation lead to the movements of tangential speed $v_{t}$ and axial speed $v_{a}$, which can be summarized to the resulting cutting speed $v_{\mathcal{C}}[7,26]$. Thus, the cutting speed can be calculated by Equation (1):

$$
v_{c}=\sqrt{v_{t}^{2}+v_{a}^{2}}
$$

By implementing several microfinishing steps with subsequently decreasing grain size, typical microfinished surfaces can be produced [7]. The first microfinishing step, rough microfinishing, is generally used to remove the typical initial ground surface by reducing the profile peaks and generating crossing honing grooves. Due to the material removal mechanisms, lateral bulges often appear along the honing grooves. These should be removed within the further process steps, the so-called fine microfinishing. The resulting surface has a typical microfinished plateau topography characterized by homogenous valleys in a cross-grid pattern and flat areas or plateaus without profile peaks [2,3,7]. In addition, these surfaces have a high bearing area ratio. The material removal mechanisms that influence the roughness and bearing surface ratio are determined by the tool specifications, process parameters, and workpiece properties $[2,7,27,28]$. The material removal mechanisms in microfinishing processes can be assumed as an interaction of mechanisms like microcracking and microfatigue, and mechanisms of microridging, microploughing, and microcutting, analogous to longitudinal stroke honing processes [26,29-32].

Due to tool selection and process parameters, the material removal volume can be controlled and the microfinishing process enables surface conditioning in distinct ways. Regarding the small material removal ratios, it is possible to change the initial surface topography without removing the complete topography. This possibility has been used to generate combined surface topography combining the features of an initially milled and a microfinished surface topography [2,7]. 
Due to the effect of low material removal while microfinishing, it is used for these investigations as substrate pretreatment for a high performance multilayer component. The goal is to generate a homogenous topography which improves the coating's interface. Therefore, different surface topographies based on a turning topography should be produced. On the one hand, the initial surface topography is partly removed. On the other hand, the turned surface topography should be removed completely, thus a microfinished plateau topography occurs.

\section{Materials and Methods}

For the investigations, 100Cr6 (AISI 52100) steel bars with $13 \mathrm{~mm}$ diameter and a length of $226 \mathrm{~mm}$ were used as substrate. The bearing steel was heat treated to a hardness of $45 \pm 2 \mathrm{HRC}$ and straightened afterwards. The initial surface for both microfinished surfaces was the same turning topography as shown in Figure 2. The turned topography is depicted by an exemplary extract of the profile and its material ratio curve in Figure 2a. Additionally, Figure $2 b$ shows a boxplot diagram build by the measured values of the maximum profile height $\mathrm{Rz}$, the core roughness $\mathrm{Rk}$, the reduced peak height Rpk, and the reduced valley depth according to the international standards DIN EN ISO 4287 and DIN EN IS0 $13565[33,34]$.

a)

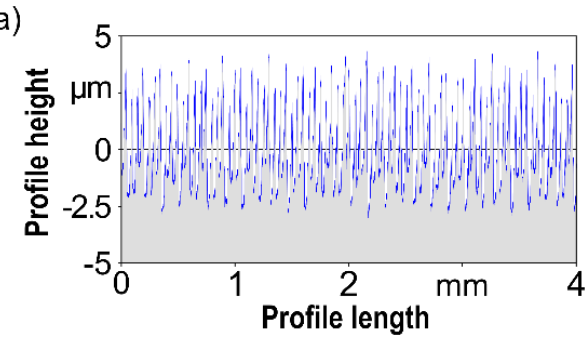

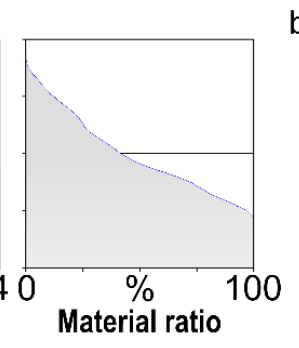

b)

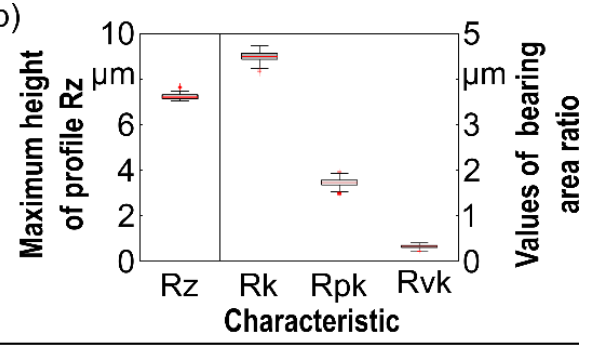

\section{Workpiece}

Workpiece material: $100 \mathrm{Cr} 6$

Workpiece hardness: $45 \pm 2 \mathrm{HRC}$

\section{Tool specifications and process parameters}

Insert material: $\mathrm{TiCN}$ coated $\mathrm{CBN}$

Feed $f$ :
Depth of cut $a_{p}: \quad 0,25 \mathrm{~mm}$

Cutting velocity $v_{c}: 30 \mathrm{~m} \mathrm{~min}^{-1}$

Figure 2. Overview of the initially turned surface by means of (a) the profile and material ratio curve and (b) surface values.

These measurements were done using a confocal white-light microscope Nanofocus $\mu$ surf $C$ with an optical module 320 S. In accordance with DIN EN ISO 4287, the suitable measuring section and the corresponding filtering system were used for the evaluation of the roughness and material content parameters. Further information on the measurement system and the evaluation strategy is given in Table 1.

Table 1. Information on roughness measurements and evaluation.

\begin{tabular}{|c|c|c|c|c|c|}
\hline \multicolumn{3}{|c|}{$\begin{array}{l}\text { Measuring System: } \\
\text { Nanofocus } \mu \text {-surf } C\end{array}$} & \multicolumn{3}{|c|}{ 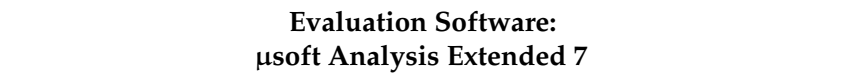 } \\
\hline \multirow{5}{*}{ Objective } & Manufacturer: & Olympus & \multirow{5}{*}{$\begin{array}{l}\text { Evaluation } \\
\text { Method }\end{array}$} & Form-elimination: & Polynomial 2. Level \\
\hline & Nomenclature: & $320-S$ & & No. of evaluated profiles: & 250 \\
\hline & Magnification: & $50 \times$ & & Filtering technique: & Gaussian filter \\
\hline & Numerical aperture: & 0.46 & & Evaluated profile length $l_{n}$ : & $\begin{array}{l}4.80 \mathrm{~mm}(\mathrm{Rz}>0.5 \mu \mathrm{m}) \\
1.50 \mathrm{~mm}(\mathrm{Rz}<0.5 \mu \mathrm{m})\end{array}$ \\
\hline & Vertical resolution: & $5 \mathrm{~nm}$ & & Cut-off length $\lambda_{c}$ : & $\begin{array}{l}0.80 \mathrm{~mm}(\mathrm{Rz}>0.5 \mu \mathrm{m}) \\
0.25 \mathrm{~mm}(\mathrm{Rz}<0.5 \mu \mathrm{m})\end{array}$ \\
\hline
\end{tabular}

Based on the area measurements, 250 profiles were used for each evaluation of the surface characteristics. The boxplots shown in the images can be created from this. The boxes contain $75 \%$ of all measured values, and the median is shown as a red line. The whiskers mark the maximum or 
minimum measured value. Values that are more than 1.5 times the box height distance from the box's upper or lower limits are marked by the statistics software MatLab used for evaluation as outliers. These are shown as red crosses.

The turned surface shown here is characterized by its typical periodic profile and nearly linear falling material ratio curve. The maximum peak height of the turned initial surface is about $\mathrm{Rz}=9 \mu \mathrm{m}$. According to ISO 13565-2 [34], the values of bearing area ratio should only be calculated for " $\mathrm{S}$ "-shaped material ratio curves. The illustration of the characteristic values at this point therefore only serve as a completion with regard to later figures. However, the consideration of the characteristic values as such according to DIN EN ISO 13565-2 for the turned surface is not expedient.

In comparison, Figure 3 shows a profile, material ratio curve as well as the surface values for a sandblasted surface. It becomes particularly clear that the surface has a higher roughness due to sandblasting and does not have a homogeneous repeating structure.

a)

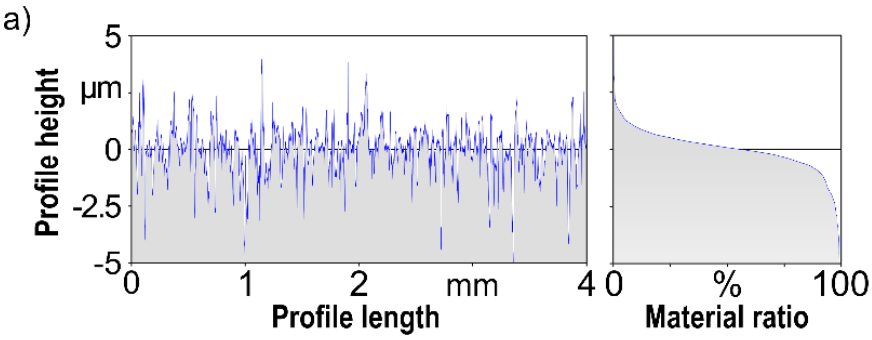

b)

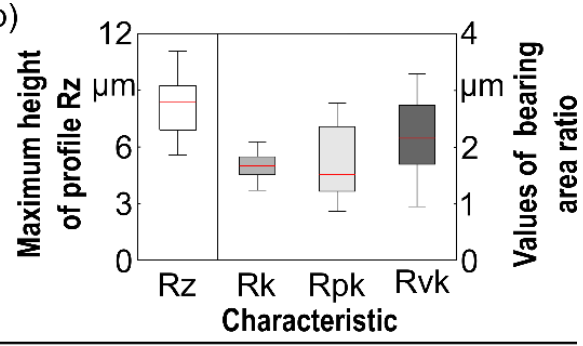

Workpiece

Workpiece material: $100 \mathrm{Cr} 6 \quad$ Workpiece hardness: $45 \pm 2$ HRC

Tool specifications and process parameters - manual sandblasting

Abrasive Grain: $\mathrm{Al}_{2} \mathrm{O}_{3} \quad$ Gritsize: $\mathrm{F} 110 \quad$ Jet pressure $p_{s}: 3$ bar Jet distance $l_{j}: 100 \mathrm{~mm} \quad$ Jet angle $a_{j}: 45^{\circ}$

Figure 3. Overview of a sandblasted surface by means of (a) the profile and material ratio curve and (b) surface values.

The microfinishing of the turned surface was carried out on an RS $600 \mathrm{C} \mathrm{Cl}$ cylindrical grinding machine from Geibel \& Hotz Maschinen und Werkzeuge GmbH. For this purpose, the NBFG 5 belt-finishing device from NAGEL Maschinen- und Werkzeugfabrik $\mathrm{GmbH}$, implemented in the machine control system, was used. Figure 4 shows the external round lathe within the belt-finishing device and the machining movements for microfinishing.

The infeed movement of the microfinishing belt at the beginning of the process was achieved by the air pressure inside a cylinder, whereby the piston performed the tools infeed in normal direction of the workpiece. The constant pressure inside the cylinder during machining resulted in a force-controlled process with the normal force $F_{n}$.

The microfinishing was carried out without any cooling, as the microfinishing is a so-called cold process and microfinishing belts do not require any lubricant at constant belt feed. To ensure the production of different surface topographies and to alternate the induced residual stresses by using similar initial surfaces, different strategies for microfinishing were used. On the one hand, the "fine" microfinishing strategy with a resulting cutting speed of $v_{c}=25.5 \mathrm{~m} \mathrm{~min}^{-1}$ was combined with a number of six axial overruns on the workpiece. On the other hand, the so-called "rough" microfinishing strategy was carried out within a cutting speed of $v_{c}=12.7 \mathrm{~m} \mathrm{~min}^{-1}$ combined with only two axial overruns. For both strategies, two microfinishing steps were realized with the aim to produce patterned honing grooves and a plateau surface and, in the case of rough microfinishing, some plateau areas. The tool was varied for each microfinishing step by using different grainsizes and orientations. In the case of the first finishing step, a microfinishing belt with $\mathrm{Al}_{2} \mathrm{O}_{3}$-grains, grain size $d_{K}=30 \mu \mathrm{m}$, was used. These grains are electrostatically-oriented, so they can produce a relatively high material removal. A tool with gravity-scattered $\mathrm{Al}_{2} \mathrm{O}_{3}$-grains with the size of $d_{K}=9 \mu \mathrm{m}$ was used for the final microfinishing steps in the case of fine and rough microfinishing. An overview showing the 
different parameters for all microfinishing steps of both strategies, fine microfinishing as well as the rough microfinishing, is given in Table 2.

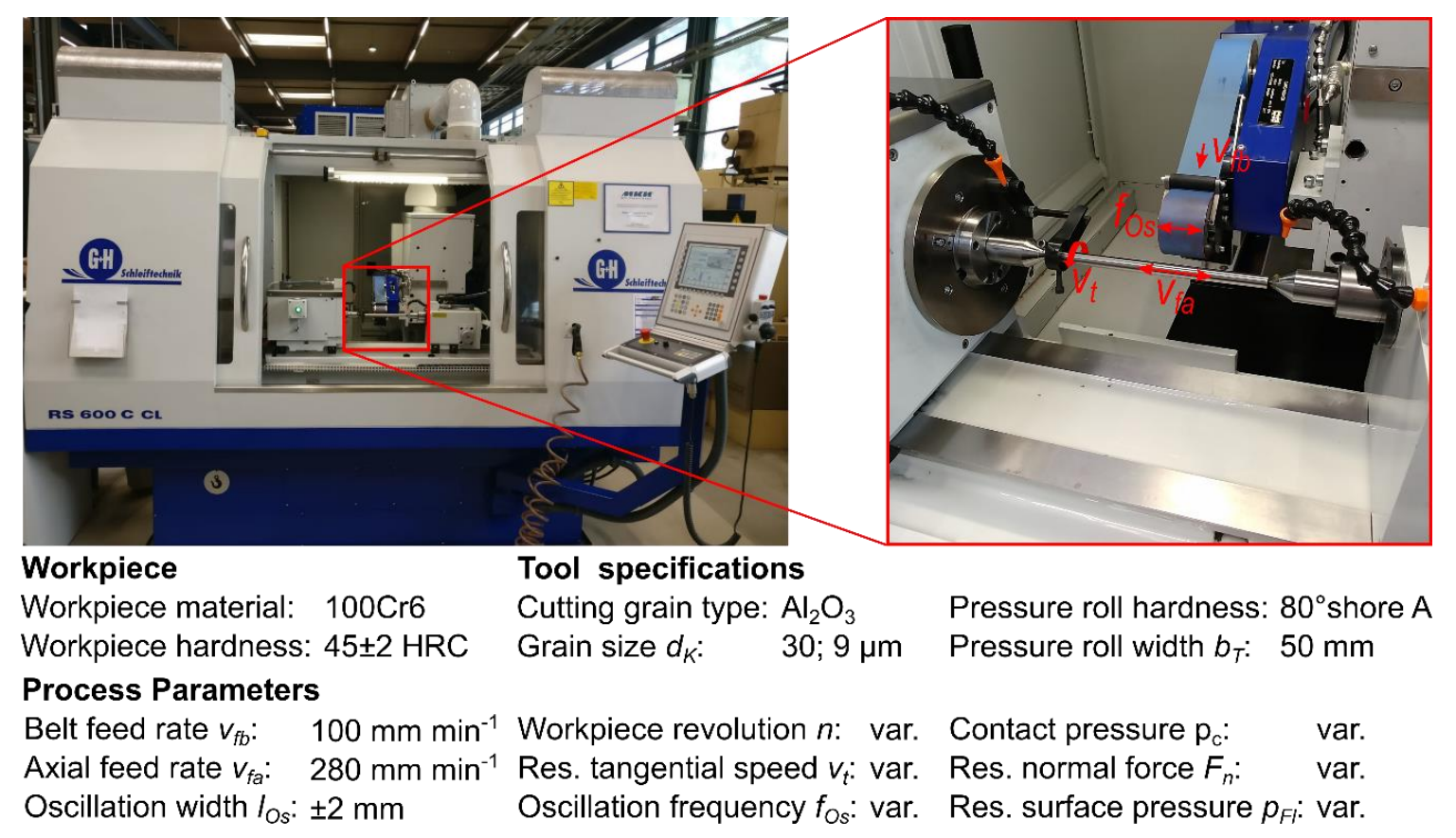

Figure 4. Overview of the experimental set-up periphery using a cylindrical grinding machine and a belt-finishing device.

Table 2. Process parameters and tool specifications on the microfinishing steps.

\begin{tabular}{cccccc}
\hline \multicolumn{2}{c}{ Microfinishing Strategy } & \multicolumn{2}{c}{ Fine Microfinishing } & \multicolumn{2}{c}{ Rough Microfinishing } \\
\hline \multicolumn{1}{c}{ Finishing Step } & 1. Step & 2. Step & 1. Step & 2. Step \\
\cline { 2 - 6 } & Grain size $d_{K}$ & $30 \mu \mathrm{m}$ & $9 \mu \mathrm{m}$ & $30 \mu \mathrm{m}$ & $9 \mu \mathrm{m}$ \\
\cline { 2 - 6 } & Grain orientation & Electrostatically-oriented & Gravity-scattered & Electrostatically-oriented & Gravity-scattered \\
\cline { 2 - 6 } $\begin{array}{c}\text { Parameter/Toon } \\
\text { Specification }\end{array}$ & Normal Force $F_{n}$ & $240 \mathrm{~N}$ & $120 \mathrm{~N}$ & $120 \mathrm{~N}$ & $120 \mathrm{~N}$ \\
\cline { 2 - 6 } & Res. surface pressure $p_{F L}$ & $2 \mathrm{~N} \mathrm{~mm}^{-2}$ & $0.95 \mathrm{~N} \mathrm{~mm}^{-2}$ & $0.95 \mathrm{~N} \mathrm{~mm}^{-2}$ & $0.95 \mathrm{~N} \mathrm{~mm}^{-2}$ \\
\cline { 2 - 6 } & Tangential velocity $v_{t}$ & $22.7 \mathrm{~m} \mathrm{~min}^{-1}$ & $22.7 \mathrm{~m} \mathrm{~min}^{-1}$ & $11.3 \mathrm{~m} \mathrm{~min}^{-1}$ & $11.3 \mathrm{~m} \mathrm{~min}^{-1}$ \\
\cline { 2 - 6 } & Oscillation frequency $f_{O}$ & $15.4 \mathrm{~Hz}$ & $15.4 \mathrm{~Hz}_{3}$ & $7.7 \mathrm{~Hz}$ & $7.7 \mathrm{~Hz}^{-1}$ \\
\cline { 2 - 6 } & Res. cutting velocity $v_{\mathcal{y}}$ & $25.5 \mathrm{~m} \mathrm{~min}^{-1}$ & $25.5 \mathrm{~m} \mathrm{~min}^{-1}$ & $12.7 \mathrm{~m} \mathrm{~min}^{-1}$ & $12.7 \mathrm{~min}^{-1}$ \\
\hline
\end{tabular}

A Computerized-Carbide Jet System K5.2 (C-CJS K5.2) from Thermico GmbH was used to deposit the HVOF-WC-Co coatings. A commercially available WC-12Co (Woka 3102, Oerlikon Metco, USA), agglomerated and sintered spheroidal powder with the grain size of $d_{K}=-45+15 \mu \mathrm{m}$, was used as feedstock powder. The spray parameters, which were used for the deposition, were determined in preliminary tests and are listed in Table 3. These parameters are capable of producing optimum coatings with low porosity, high homogeneity, and relatively smooth surface.

Table 3. Spray parameters of WC-12Co sprayed coating.

\begin{tabular}{|c|c|c|c|c|c|c|c|c|}
\hline \multicolumn{4}{|c|}{ Spray Parameters (Volume Flow) } & \multicolumn{2}{|c|}{ Powder Feed } & \multicolumn{3}{|c|}{ Spray Gun Movement } \\
\hline $\begin{array}{c}\text { Kerosene } \\
\text { Exxsol D60 }\end{array}$ & Oxygen $\mathrm{O}_{2}$ & $\begin{array}{c}\text { Hydrogen } \\
\mathrm{H}_{2}\end{array}$ & $\begin{array}{c}\text { Nitrogen } \\
\mathrm{N}_{2}\end{array}$ & Feed $f_{\text {prop }}$ & $\begin{array}{l}\text { Injection } \\
\text { rate }\end{array}$ & $\begin{array}{c}\text { Spray } \\
\text { distance }\end{array}$ & $\begin{array}{c}\text { Axial velocity } \\
v_{a}\end{array}$ & Over-runs \\
\hline $201 \mathrm{~h}^{-1}$ & $8001 \mathrm{~min}^{-1}$ & $501 \mathrm{~min}^{-1}$ & $101 \mathrm{~min}^{-1}$ & $4.2 \%$ & $50 \mathrm{~g} \mathrm{~min}^{-1}$ & $300 \mathrm{~mm}$ & $17.5 \mathrm{~m} \mathrm{~min}^{-1}$ & 20 \\
\hline
\end{tabular}


The surfaces of all substrates that had not been machined were roughened by sandblasting using $\mathrm{F} 110 \mathrm{Al}_{2} \mathrm{O}_{3}$ grains. The jet pressure of the blasting gun was set to $p_{j e t}=0.3 \mathrm{MPa}$, and the distance was kept to $100 \mathrm{~mm}$ at a jet angle of $45^{\circ}$. The blasting time was approximate $45 \mathrm{~s}$ for each substrate surface.

The phase composition of all samples and the obtained coatings were investigated by an X-ray diffraction (XRD) device using $\mathrm{Cr}-\mathrm{K} \alpha 1$. All measurements were done by using LYNXEYE XE detector (Bruker Advanced D8 diffractometer). The induced residual stresses of the turned and microfinished substrates were determined by the same device. The measurements were done for $2 \theta 106.6^{\circ}$ (Fe 200 ). The investigated range of high diffraction angle $2 \theta$ is between $103.5^{\circ}$ and $108.5^{\circ}$ in a step size of $0.1^{\circ}$ and $3.5 \mathrm{~s}$ scanning time. The Phi angle was used at $0^{\circ}$ and $180^{\circ}$, while Chi was varied between $0^{\circ}$ and $60^{\circ}$ in eight steps. The residual stresses were calculated based on the changes in the distance of a lattice plane for different inclination angles $(\psi)$. For the calculation of the residual stresses, a Poison ratio of 0.3 and a Young's modulus of 210 GPa were used. Additionally, the used elastic constants were $\mathrm{S} 1=-1.429 \times 10^{-6} \mathrm{MPa}^{-1}$ and $1 / 2 \mathrm{~S} 2=6.190 \times 10^{-6} \mathrm{MPa}^{-1}$. The distance change as a function of inclination angles was analyzed with the Bruker software Leptos, and the exact values of the residual stresses were determined using the $\sin \psi$ method according to $[35,36]$.

\section{Results}

This chapter shows the results of the experimental investigations within different figures depicting diagrams, cross section pictures, and topography measurements as well. In addition to the presentation, the influence of the machining processes on the surface integrity were analyzed as far as possible.

\subsection{Resulting Surfaces for the Fine Microfinishing Strategy}

In this section, the results of the fine microfinishing experiments are shown and analyzed as well. With the aim of producing a plateau finished surface, the turned surface was machined with two steps of microfinishing at a cutting velocity of $v_{c}=25.5 \mathrm{~m} \mathrm{~min}^{-1}$. In order to achieve a high material removal rate to remove efficiently particularly the peaks of the turned topography, the process pressure was chosen as high as possible. Figure 5 shows the profile material ratio curve and some surface values for the first step of fine microfinishing.

a)

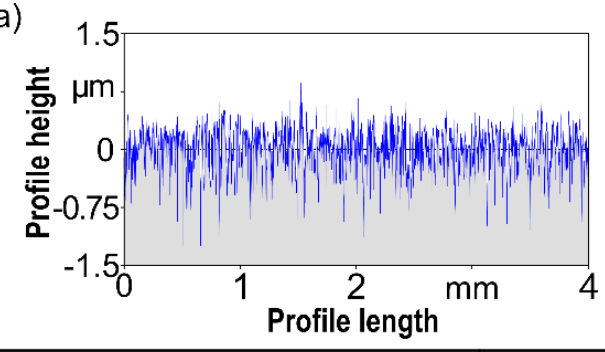

b)
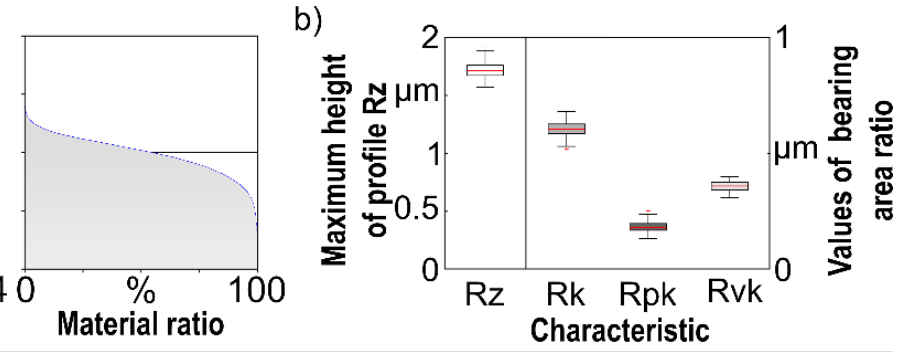

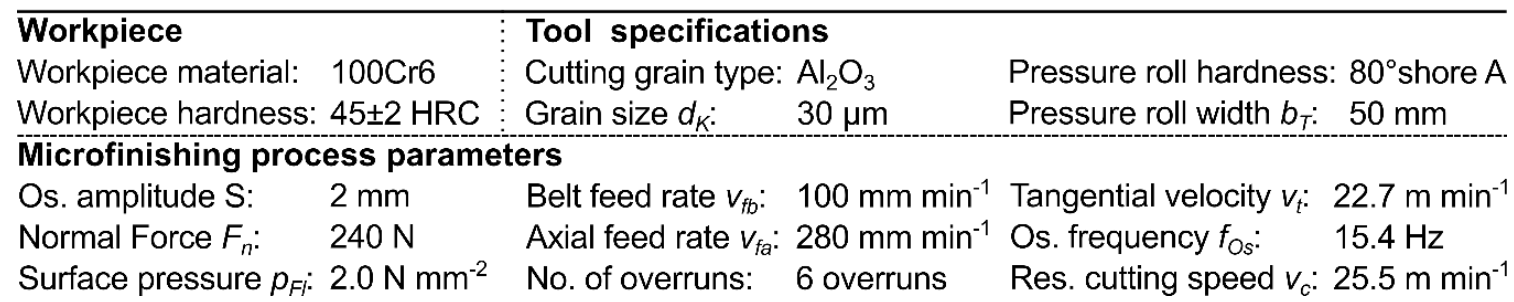

Figure 5. Resulting surface for the first fine microfinishing step by means of (a) the profile and material ratio curve and (b) surface values.

As can be seen in Figure 5, the periodic profile of the initially turned surface is no longer apparent. The profile appears rather aperiodic and is characterized by many low and high points within the scale. A closer look reveals that the negative values dominate, which means there are more grooves than peaks. 
The material ratio curve is now described by different gradients and is approximately " $\mathrm{S}$ "-shaped. Thus, the values of bearing area ratio can be analyzed, as well as the maximum peak height of the profile. Compared to typical microfinished surfaces, a maximum peak height of the profile $\mathrm{Rz}$ up to $1.8 \mu \mathrm{m}$ can be described as high. Taking the grain size and the electrostatic grain orientation into account, this is a typical Rz-value, especially when it is not the last microfinishing step. Although, the median Rvk to Rpk ratio is approximately 1.8 , this surface is not a plateau topography. This can be confirmed by the consideration of further parameters, since the sole consideration of the RVK/Rpk ratio is not sufficient to define a plateau topography. The core roughness $\mathrm{Rk}$ is relatively high, respectively significantly higher than Rvk. This is a criterion for the fact that the surface at hand cannot be regarded as a plateau. In conclusion, the first step of fine microfinishing produces an aperiodic surface with a higher amount of valleys in comparison to peaks. However, peaks still appear, thus a second microfinishing step is necessary to produce a plateau-textured surface.

Figure 6 shows the same graphs and diagrams with respect to the surface of the second fine microfinishing step. In this case, the scale for all graphs and values decreases from the first to the second step because the surface is smoothed.

a)

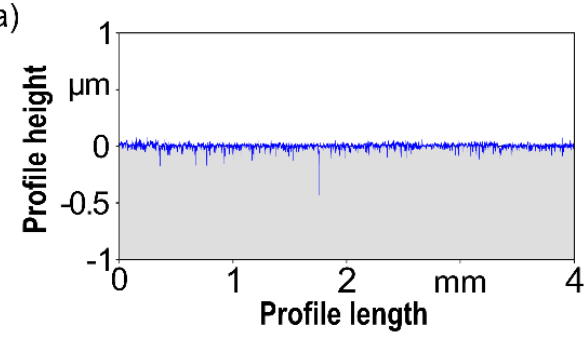

b)
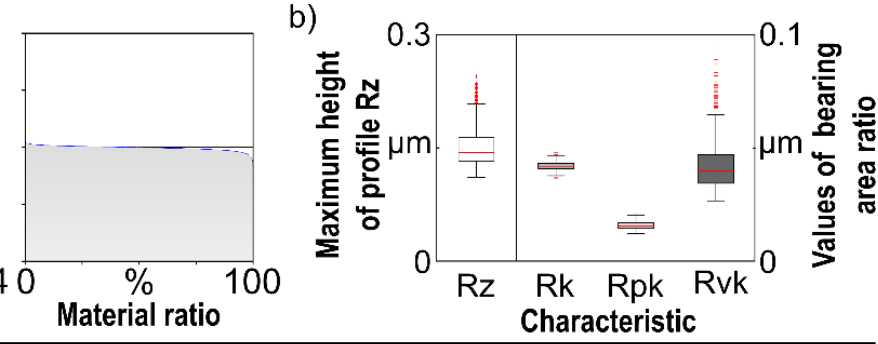

\section{Workpiece}

Workpiece material: $100 \mathrm{Cr} 6$

Workpiece hardness: $45 \pm 2$ HRC

\section{Microfinishing process parameters}

Os amplitude $S$ : $2 \mathrm{~mm}$

Normal Force $F_{n}$ : $\quad 120 \mathrm{~N}$

Surface pressure $p_{F i}: 0.95 \mathrm{~N} \mathrm{~mm}^{-2} \mathrm{~N}$

\section{Tool specifications}

Cutting grain type: $\mathrm{Al}_{2} \mathrm{O}_{3}$ $9 \mu \mathrm{m}$

Belt feed rate $v_{t b}: 100 \mathrm{~mm} \mathrm{~min}^{-1}$ Tangential velocity $v_{t}: 22.7 \mathrm{~m} \mathrm{~min}^{-1}$ Axial feed rate $v_{f a}: 280 \mathrm{~mm} \mathrm{~min}^{-1}$ Os. frequency $f_{\mathrm{Os}}: \quad 15.4 \mathrm{~Hz}$ No. of overruns: 6 overruns
Pressure roll hardness: $80^{\circ}$ shore $\mathrm{A}$ Pressure roll width $b_{T}: 50 \mathrm{~mm}$

Figure 6. Resulting surface for the second fine microfinishing step by means of (a) the profile and material ratio curve and (b) surface values.

The profile appears as smooth surface within frequent small cavities and nearly no peaks. There is one dominant cavity outstanding with a depth close to $0.5 \mu \mathrm{m}$. The material ratio curve is characterized by a huge flat area and its " $\mathrm{S}$ "-shaped form. The maximum height of profile $\mathrm{Rz}$ is reduced from the first microfinishing step by the secondary microfinishing step to values between $R z=0.2$ up to $0.45 \mu \mathrm{m}$. In comparison to the first microfinishing step, the values of bearing area ratio now describe a plateau-textured surface. The reduced valley depth Rvk is significantly higher than the reduced peak height Rpk (for the median values Rvk/Rpk approximately 2) and, additionally, the core roughness Rk is relatively low. In summary, it can be stated that after the second fine microfinishing step, a smooth plateau surface with very small valleys is achieved.

\subsection{Resulting Surface for the Rough Microfinishing Strategy}

Starting with the first rough microfinishing step, Figure 7 depicts the profile curve and the material ratio curve (a), as well as the characteristics of the surface described by Rz, Rk, Rpk, and Rvk. Analogous to the processing steps of fine microfinishing, the results of rough microfinishing are now presented.

Considering the profile resulting from the first rough microfinishing step, it is apparent that the initial turning topography is not completely removed. The profile remains periodic, whereby the peaks and valleys are not as high as before, compared to Figure 2. With respect to the measured values, the surface is not plateau-textured, even if the ratio of Rvk/Rpk is greater than 1 . The microfinishing 
process leads to a reduction of the peaks of the turned surface. The parameters, especially the cutting frequency and the number of overruns, are sufficient to generate a surface where periodic elements of the turning process remain.

Subsequent to the first rough microfinishing step, the second step was performed using a gravity-scattered $9 \mu \mathrm{m} \mathrm{Al}{ }_{2} \mathrm{O}_{3}$ microfinishing belt. The resulting profile, material ratio curve and the surface values are summarized in Figure 8.

a)

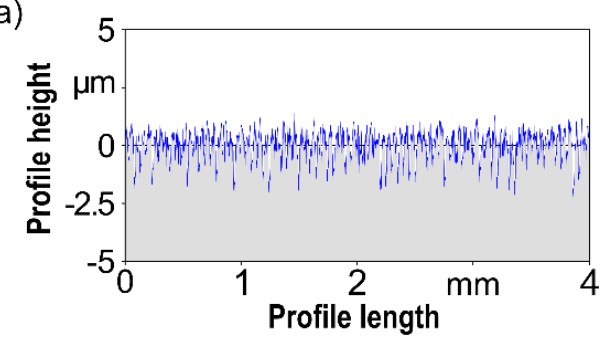

b)

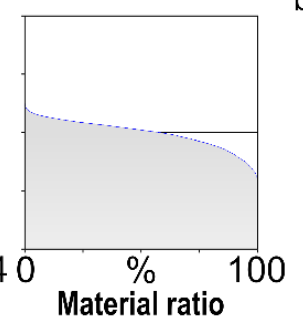

b)

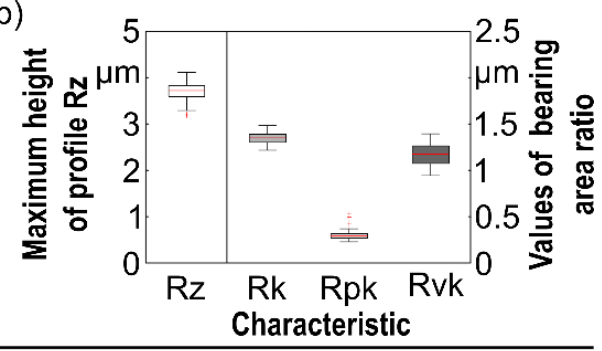

Workpiece

Tool specifications

Workpiece hardness: $45 \pm 2 \mathrm{HRC}$ ! Grain size $d_{k}: \quad 30 \mu \mathrm{m}$

Microfinishing process parameters

Os. amplitude $S: \quad 2 \mathrm{~mm} \quad$ Belt feed rate $v_{t b}: 100 \mathrm{~mm} \mathrm{~min}^{-1}$ Tangential velocity $v_{t}: 11.3 \mathrm{~m} \mathrm{~min}^{-1}$ Normal Force $F_{n}: \quad 120 \mathrm{~N} \quad$ Axial feed rate $v_{f a}: 280 \mathrm{~mm} \mathrm{~min}^{-1}$ Os. frequency $f_{O s}: \quad 7.7 \mathrm{~Hz}$ Surface pressure $p_{F F}: 0.95 \mathrm{~N} \mathrm{~mm}^{-2}$ No. of overruns: 2 overruns Res. cutting speed $v_{c}: 12.7 \mathrm{~m} \mathrm{~min}^{-1}$

Figure 7. Resulting surface for the first rough microfinishing step by means of (a) the profile and material ratio curve and $(\mathbf{b})$ surface values.

a)

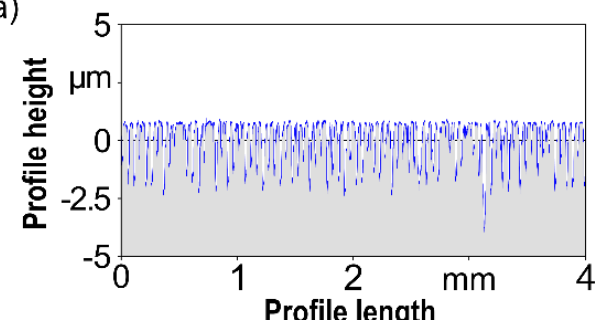



Material ratio b)

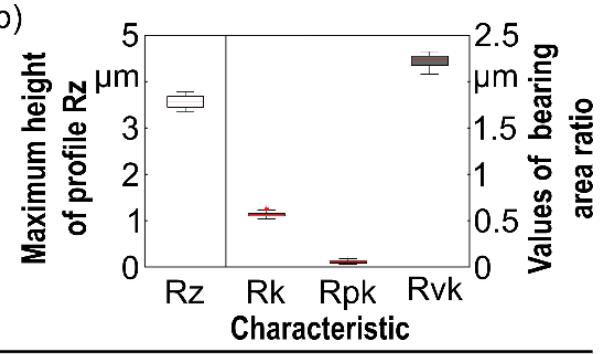

\section{Workpiece}

Tool specifications

Workpiece material: $100 \mathrm{Cr} 6 \quad$ Cutting grain type: $\mathrm{Al}_{2} \mathrm{O}_{3}$

Workpiece hardness: $45 \pm 2$ HRC $\vdots$ Grain size $d_{K}: \quad 9 \mu \mathrm{m}$

\section{Microfinishing process parameters}

Os. amplitude $S: \quad 2 \mathrm{~mm} \quad$ Belt feed rate $v_{t b}: 100 \mathrm{~mm} \mathrm{~min}^{-1}$ Tangential velocity $v_{t}: 11.3 \mathrm{~m} \mathrm{~min}^{-1}$ Normal Force $F_{n}: \quad 120 \mathrm{~N} \quad$ Axial feed rate $v_{f a}: 280 \mathrm{~mm} \mathrm{~min}^{-1}$ Os. frequency $f_{O S}: \quad 7.7 \mathrm{~Hz}$ Surface pressure $p_{F}: 0.95 \mathrm{~N} \mathrm{~mm}^{-2}$ No. of overruns: 2 overruns $\quad$ Res. cutting speed $v_{c}: 12.7 \mathrm{~m} \mathrm{~min}^{-1}$

Figure 8. Resulting surface for the second rough microfinishing step by means of (a) the profile and material ratio curve and $(\mathbf{b})$ surface values.

The profile is smoothed and the highest elevations appear less peaked than before. There are dominant cavities which have a depth of around $3 \mu \mathrm{m}$ when measuring from the top of the profile. The smoothed profile appearance on the top is also reflected by the material ratio curve. Taking the first $50 \%$ material ratio into account, the curve is nearly the same as the final fine microfinished surface. Even if the material ratio curve is not " $\mathrm{S}$ "-shaped in this case, an analysis of the values of the bearing area ratio seems appropriate. The remaining surface has a maximum profile height of $\mathrm{Rz}=3.5$ to $4 \mu \mathrm{m}$ and thus is not describing a smooth surface. The ratio of Rvk/Rpk is nearly 10 , while the core roughness is also significantly lower than the reduced valley depth. This relation describes a plateau-like texture, although the material ratio curve is not " $\mathrm{S}$ "-shaped. The elevated parts of the surface are plateaus, while the remaining turning topography can be indicated by the deep cavities. 


\subsection{Residual Stresses}

In addition to the surface measurements, the residual stress $\sigma$ was measured for every machining state. Because of the shape and diameter of the workpieces, it was not possible to measure the residual stress curve by means of borehole method. That is why the X-ray-diffraction method was used to measure the residual stress in the workpiece surface. Figure 9 shows the measured residual stresses along the machining steps.

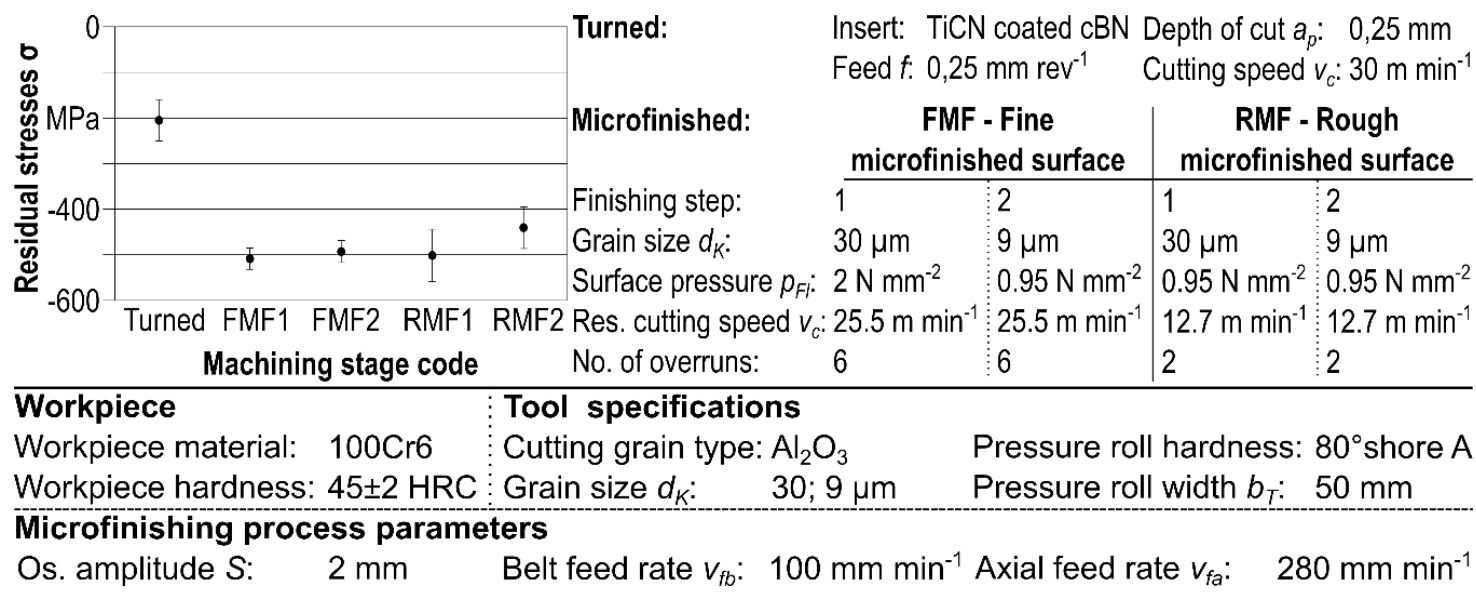

Figure 9. Residual stresses after surface machining by turning and microfinishing.

Here, it is noticeable that the induced residual stresses by turning the workpiece are compressive stresses of $\sigma=-200 \mathrm{MPa}$. An increase of the induced compressive residual stresses $\sigma=-500 \mathrm{MPa}$ was recorded after the different microfinishing steps. The variation of grainsize and grain-orientation for the different microfinishing belts, as well as the exerted surface pressure while fine finishing, have no effect on the induced residual stresses.

Regarding the different parameters in the first microfinishing step of both strategies, fine and rough microfinishing, it is not possible to explain how each one influences the residual stress. In the case of simultaneous change of the surface pressure, the cutting velocity, and the number of overruns, the factors may interact, so the resulting residual stresses are the same. In the case of the second microfinishing step, it is assumed that the relatively low material removal due to the small grit size does not further influence the residual stresses.

\subsection{Detailed Analysis of the Topography Modification}

The obtained surface patterns were analyzed by 3D-topographical depictions of $200 \times 200 \mu \mathrm{m}$ combined with an exemplary profile of $200 \mu \mathrm{m}$ length. In addition, for each machining step, a cross section was generated and inspected with a scanning electron microscope (SEM). Figure 10 shows these analyses for the sandblasted workpiece.

For the sandblasted topography, the irregular appearance of the roughened surface is clearly visible-especially due to the wider cavities or notches, the surface appears fissured. It becomes clear that no patterning of the surface has been achieved, and therefore no homogeneous topography is present.

For the machining strategy of turning and microfinishing, the development of the surface topography is represented for the individual machining steps. For this purpose, for fine microfinishing, the initial surface topography, a profile writing, and the SEM image after (a) turning, as well as the modified topographies after (b) one and (c) two fine microfinishing steps are shown in Figure 11. 
a)

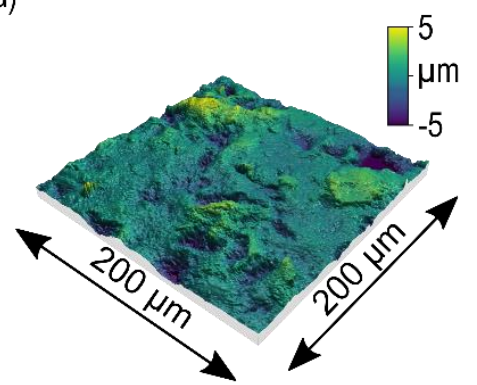

b)

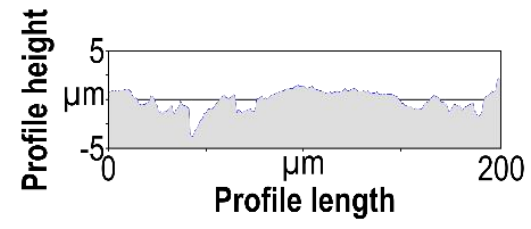

c)

\section{$50 \mu \mathrm{m}$}

\section{Workpiece}

Workpiece material: $100 \mathrm{Cr} 6$ Workpiece hardness: $45 \pm 2$ HRC

\section{Tool specifications and process parameters - manual sandblasting}

Abrasive Grain: $\mathrm{Al}_{2} \mathrm{O}_{3}$ Gritsize: F110 Jet pressure $p_{s}: 3$ bar Jet distance /: $100 \mathrm{~mm}$ Jet angle $\alpha_{j}: 45^{\circ}$

Figure 10. Sandblasted surface topography. (a) 3D-topography (b) detailed profile, and (c) cross section SEM picture for a coated workpiece.

a)

Turned initial surface:

$f=0,25 \mathrm{~mm} \mathrm{rev}^{-1}$;

$a_{p}=0,25 \mathrm{~mm}$;

$v_{c}=30 \mathrm{~m} \mathrm{~min}^{-1}$

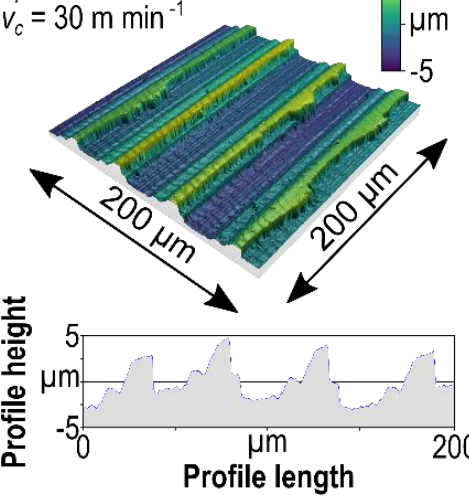

Profile length

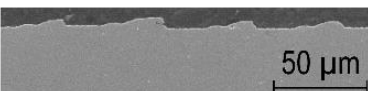

\section{Workpiece}

Workpiece material: $100 \mathrm{Cr} 6$

Workpiece hardness: $45 \pm 2$ HRC

Microfinishing process parameters

Os. amplitude $S$ : $\quad 2 \mathrm{~mm}$

Normal Force $F_{n}: \quad 240 ; 120 \mathrm{~N}$

b)

Fine microfinished surface - 1.Step: $d_{K}=30 \mu \mathrm{m}$;

$F_{n}=240 \mathrm{~N}$;

$p_{F l}=2 \mathrm{~N} \mathrm{~mm}^{-2}$

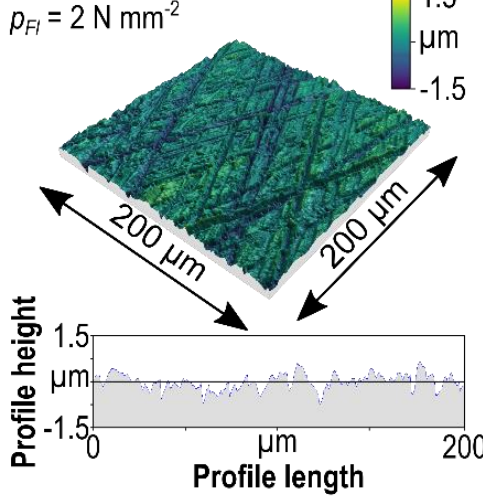

Profile length

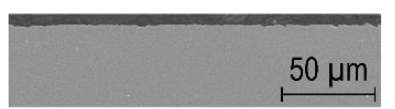

Tool specifications

Cutting grain type: $\mathrm{Al}_{2} \mathrm{O}_{3}$

Grain size $d_{K}$ :

30; $9 \mu \mathrm{m}$

Belt feed rate $v_{f b}: 100 \mathrm{~mm} \mathrm{~min}^{-1}$ Tangential velocity $v_{t}$ :

Axial feed rate $v_{f a}: 280 \mathrm{~mm} \mathrm{~min}^{-1}$ Os. frequency $f_{O S}$ : Surface pressure $p_{F i}: 2 ; 0.95 \mathrm{~N} \mathrm{~mm}^{-2}$ No. of overruns: 6 overruns $\quad$ Res. cutting speed $v_{c}: 25.5 \mathrm{~m} \mathrm{~min}^{-1}$

c)

Fine microfinished surface - 2.Step:

$30 \mu \mathrm{m}$

$\begin{array}{ll}F_{n}=120 \mathrm{~N} ; & -0.5 \\ p_{F l}=0.95 \mathrm{~N} \mathrm{~mm}^{-2} & -\mu \mathrm{m}\end{array}$

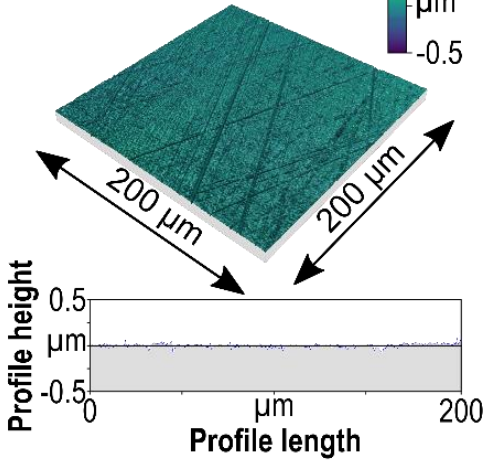

$50 \mu \mathrm{m}$

Figure 11. Topography, detailed profile, and cross section SEM picture for the machining steps (a) turned, (b) first fine microfinishing step, and (c) second fine microfinishing step.

This figure shows that the turned surface pattern is completely removed by the first fine microfinishing step. In addition, the 3D-topography shows the cross-angled microfinishing grooves which are created by the process kinematics. Due to the used microfinishing tool for the first step, lateral bulges appear next to the grooves. These bulges are typical for the first microfinishing steps, according to microgrooving and microploughing material removing mechanisms being effective while microfinishing. By using a second microfinishing step, these lateral bulges can be removed and a smoothed topography is generated. When comparing the profile extractions from the microfinishing steps, it becomes clear that the second microfinishing step also removes most of the grooves of the 
first step. This is why the remaining grooves are not as dominant and the ratio of Rvk/Rpk is not as high as possible. To increase these ratios, it might be sufficient to reduce the process time, i.e., in this case, reduce the number of overruns.

The comparison of the cross section displays the smoothening of the surface as well. The SEM magnification, in this case, seems insufficient to show the small honing grooves generated by microfinishing. Analogous to this, Figure 12 shows the topography and an extracted profile, as well as a cross section for the rough microfinishing.
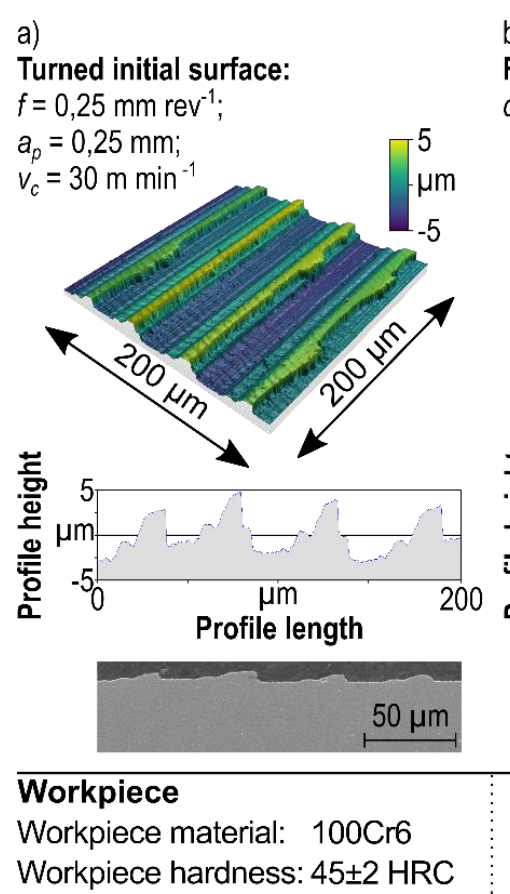

b) Rough microfinished surface - 1 .Step: Rou $d_{k}=30 \mu \mathrm{m}$

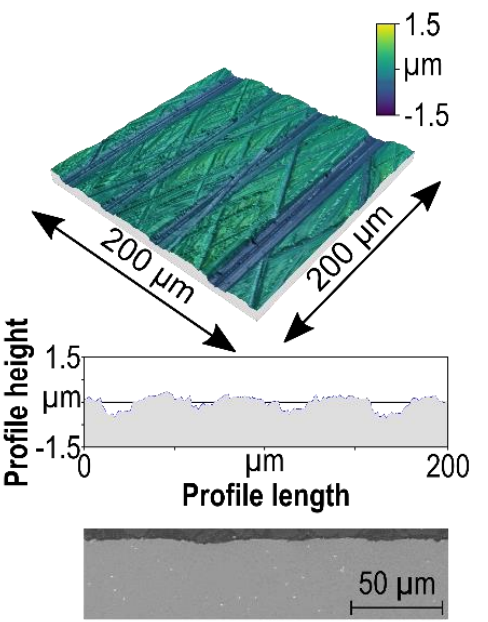

Tool specifications

Cutting grain type: $\mathrm{Al}_{2} \mathrm{O}_{3}$ Grain size $d_{k}: \quad 30 ; 9 \mu \mathrm{m}$ c) $d_{k}=9 \mu \mathrm{m}$

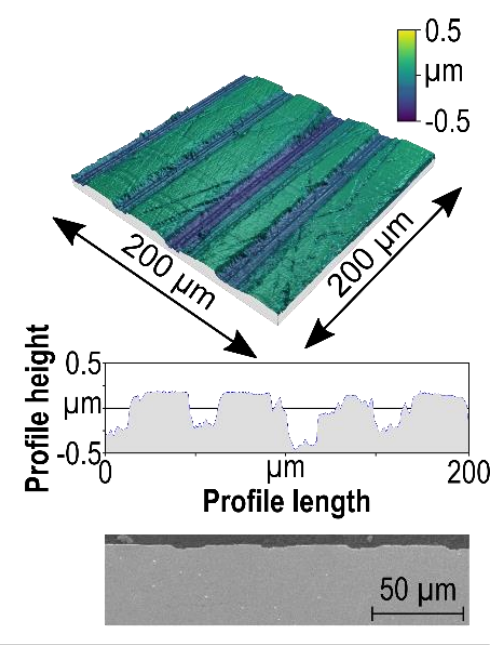

Pressure roll hardness: $80^{\circ}$ shore $\mathrm{A}$ Pressure roll width $b_{T}: 50 \mathrm{~mm}$

\begin{tabular}{|c|c|c|c|c|}
\hline \multicolumn{5}{|c|}{ Microfinishing process parameters } \\
\hline Os. amplitude $S$ : & $2 \mathrm{~mm}$ & $100 \mathrm{~mm} \mathrm{~min}^{-1}$ & Tangential velocity $v_{i}$ & $11.3 \mathrm{~m} \mathrm{~min}^{-1}$ \\
\hline Normal Force $F_{n}$ : & $120 \mathrm{~N}$ & Axial feed rate $v_{f a}: 280 \mathrm{~mm} \mathrm{~min}^{-1}$ & Os. frequency $f_{O}$ & $7.7 \mathrm{~Hz}$ \\
\hline Surface pressure $p_{F}$ & $0.95 \mathrm{~N} \mathrm{~mm}^{-2}$ & No. of overruns: 2 overruns & Res. cutting speed $v_{c}$ : & $12.7 \mathrm{~m} \mathrm{~min}^{-}$ \\
\hline
\end{tabular}

Figure 12. Topography, detailed profile, and cross section SEM picture for the machining steps (a) turned, (b) first rough microfinishing step, and (c) second rough microfinishing step.

The changes of the previously described surface based on the two-dimensional profile and the characteristic values and the material ratio curve can be illustrated by the 3D-topography, as well as the detailed profile extract and the cross section. The figure clarifies that the turning topography is modified without being completely removed. The first rough microfinishing step leads to a reduction of the peaks, since only the highest located material is removed from the surface. The contact between workpiece surface and the tool is an area whose size is dependent on workpiece diameter, microfinishing belt, and especially the contact pressure element's dimensions and hardness. Due to the elastic deformation of the tool, there is an embrace and thus surface contact between tool and workpiece. In combination with the small grit sizes and the microfinishing kinematics, it is possible to remove material step-by-step from the highest level to the lowest with microfinishing.

Analogous to the first fine finishing step, the first rough microfinishing step generates cross-angled grooves. Here the grooves are discontinuous, since the abrasive grain only cuts the highest surface level. The previously detected lateral bulges can also be seen here. Especially, the extracted profile illustrates the change of peaks and valleys on the highest profile areas. With the second rough microfinishing step, the lateral bulges are removed and the highest profile areas are turned into plateaus. The remaining topography is built by the periodic turning grooves and microfinished plateaus within very 
small honing grooves. The cross section shows that the plateaus are nearly $40 \mu \mathrm{m}$ wide. In this way, an adhesion defect-free surface pattern was produced with an outstanding reproducibility potential.

\subsection{Coating Interface}

The machined workpieces with the described topographies of the fine and the rough microfinishing strategy were coated by HVOF spraying at the Institute of Materials Engineering. WC-12Co (Woka 3102) was used as feedstock material. To analyze the effect of the machined surface pattern on the obtained coating adhesion, a sandblasted workpiece was used for comparison. The reason for this is largely due to the fact that sandblasting is the most widely used and well-established surface roughening technique in thermal spraying. Figure 13 shows the cross section SEM picture of the coating-substrate interface, which can be used for qualitative analysis of the coating's interface.

\section{a) Sandblasted substrate topography}

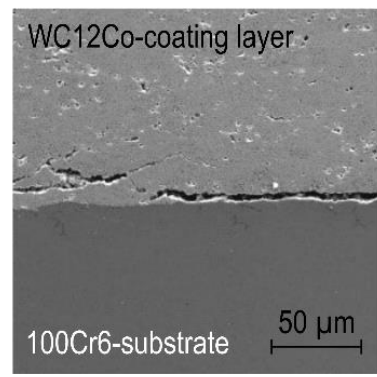

b) Machined substrate topography Turned and fine microfinished

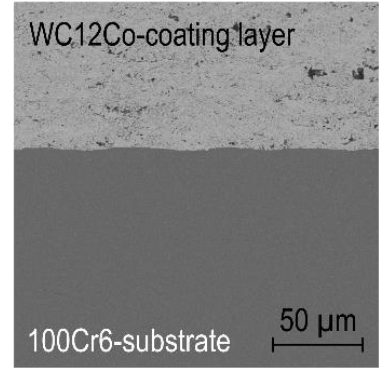

c) Machined substrate topography Turned and rough microfinished

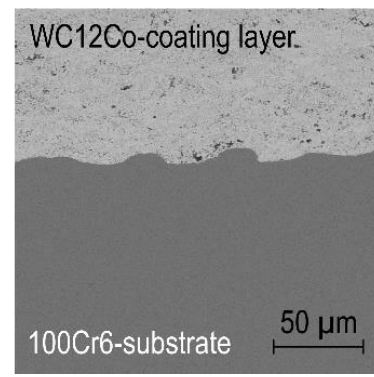

Figure 13. Cross section SEM picture on the coating interface for (a) sandblasted, (b) turned and fine microfinished, and (c) turned and rough microfinished substrate.

Even though the SEM pictures depict a clear spalling in the case of sandblasting, it does not mean that the coating interface is insufficient or worse than using microfinishing. The institute of material technologies has developed an adhesion testing procedure to test the coating adhesion by cylindrical parts, as shown in Figure 14. Here, a pull-off rod is glued to a part of the sample circumference of the workpiece using glue. The workpiece is held within a pull-off sleeve. When the pull-off rod is used within a tensile testing machine, it is pulled upwards with increasing pulling force $F_{p}$ until it tears off from the workpiece. The forces on the loaded surface are measured so that an adhesion strength can be determined.

a)

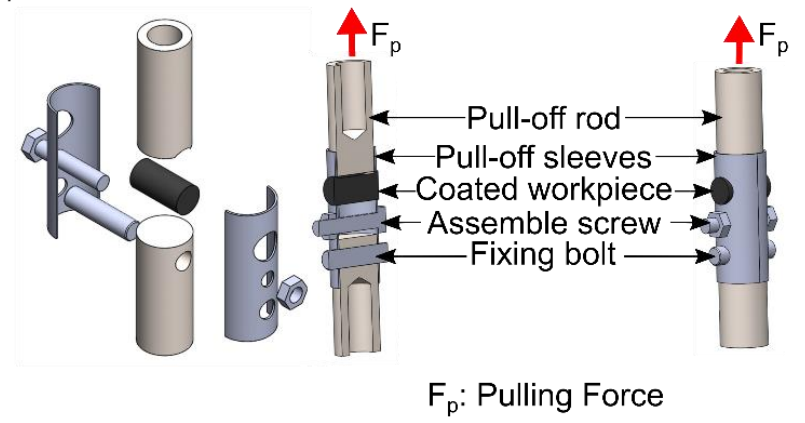

b)

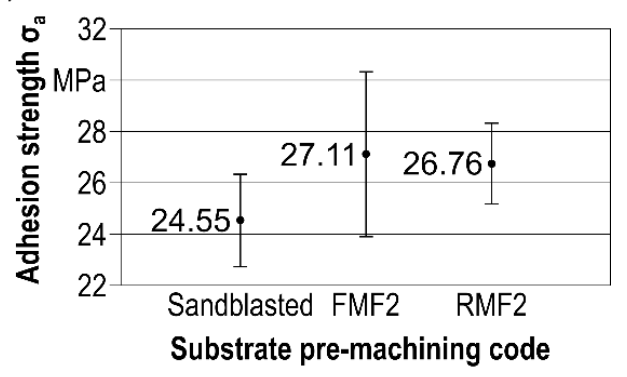

Sandblasted: Gritblasted substrate; FMF2: Fine microfinished substrate; RMF2: Rough microfinished substrate

Figure 14. Adhesion test. (a) Schematic illustration of the test design, and (b) evaluation of adhesion strength.

For each of these substrate pretreatment strategies, five adhesion tests were performed to calculate an arithmetic mean and display a minimum and maximum value for the adhesion strength. In summary, 
each sample has a higher adhesion strength than $\sigma_{a}=22 \mathrm{MPa}$. In the case of the examined workpieces, there was no separation of the coating from the substrate or the layer itself, as the adhesion of the glue had failed before. It can therefore be stated that the procedure is not well established and needs further improvement. The next study will be about the dynamic behavior of all three coated conditions.

\section{Discussion}

The experimental investigations have shown that it is possible to generate different topographies with microfinishing based on the same initial surface. The patterned topography produced here can enlarge the field of application for microfinishing processes, especially if they prove to be effective for coating adhesion and improve the flexural strength. It has been shown that microfinishing itself can be used for pretreatment, as the adhesive strength does not appear to be lower than that of a sandblasted workpiece. Since microfinishing has high process reliability and repeatability and produces a homogeneous surface topography, it is preferable to sandblasting for the pretreatment of the substrate surface.

Regarding fine microfinishing, the second process step could be shortened to generate a higher $\mathrm{Rvk} / \mathrm{Rpk}$ ratio. Due to the process kinematics and the material removal mechanisms in microfinishing, the topography is successively almost removed from the surface and not, as in other processes, completely removed with a certain cutting depth. This is due to the fact that the small grain sizes are accompanied by low grain penetration, which can be in the sub micrometer range. Thus, the removal of the initial surface therefore correlates with the process time. A shorter process time leads to less ablation of the material and a greater difference between the resulting heights and depths in the surface. This can further increase the Rvk/Rpk ratio. However, if the Abbott curve is too steep and the Rpk value is too high, it is not possible to enlarge the Rvk/Rpk ratio within the same process time. It must therefore be ensured that the peaks are removed or levelled and that deep grooves remain at the same time. In contrast, a longer microfinishing process can result in the removal of the existing grooves of the original surface structure. This leads to a reduction in both the Rpk and the Rvk values, which means that the Rvk/Rpk ratio does not increase.

As it is already known, the initial surface has a main influence on the resulting surface while microfinishing. Due to the investigations, it was shown that it is possible to use a periodic surface pattern, such as a turning topography, to realize different types of surface pattern by means of microfinishing. The strongest influence on the resulting topography within these investigations is the tool used and the process time. The tool determines the material removal by the grain size and orientation, and the resulting groove depth by the possible grain penetration depth. The process time, in turn, is the decisive control variable for the resulting surface topography, since continuous material removal takes place due to the constant belt feed. With a low material removal rate, the material removal rate can be adjusted to a high material removal rate by increasing the process time.

The residual stress measurement showed that microfinishing in the case of a force-controlled machining process, with its area contact between tool and workpiece, causes compressive residual stresses. Due to the fact that there was no difference between the first and the second fine microfinishing step, it could be helpful also to analyze the residual stress curve. A larger workpiece diameter is needed to enable the use of the borehole method for measuring the residual stresses. Also, one-factor tests regarding the parameters' surface pressure, cutting velocity, number of overruns, and respective process time, could be suitable to analyze their main influences on the residual stresses during microfinishing.

The results show that a two-dimensional view of technical surfaces can be insufficient and that, in addition to the typical roughness, other parameters should be used for the evaluation. Especially when looking at functional surfaces, a qualitative view can also be useful as it provides an extended impression. For example, the cavities of the rough microfinished surfaces in Figure 12 appear to be less steep than in the complete profile diagrams of Figures 3,7 and 8. This can be traced back to the scaling effects, which lead to a distortion or, more precisely, compression of the actual surface. Under standardized observation, it is difficult to speak of grooves and peaks as is usually done. 
Regarding the overall aim, it could be determined that the machining strategy of a combination of turning and microfinishing was useful to create homogeneous patterned topographies with outstanding reproducibility that eliminates the adhesion defects and improves the coating interface, independent from the microfinishing strategies. Further investigations have to be made to quantify the coating's adhesive bonding and the fatigue strength of the workpieces. In the case of rotationally symmetrical workpieces, there is no standardized measurement method for the coating's adhesive bonding, thus the standard only uses flat-shaped surfaces. Therefore, analogy tests were developed to measure the coating adhesion for the present workpiece geometry. However, no statements could be made about the influence of substrate pretreatment on the coating's adhesion, as the adhesion of the glue failed for all samples and the coating was not separated from the substrate.

Further research will consist of proving the suitability of these topographies for HVOF coating with a focus on verifying the advantages of the multilayer for functional properties. Therefore, additional rotating bending fatigue tests will be carried out in order to test the fatigue strength of multilayer workpieces with their different substrate surfaces. For this purpose, the coated surface will be microfinished also, to generate a smoothed surface in reference to tribological loaded components.

\section{Conclusions}

In general, the experimental investigations showed that microfinishing could be used in combination with turning to build different topographies. The X-ray diffraction method showed the potential of producing compressive residual stresses with microfinishing.

Further, the detailed view on the surface topography allows the statement that, especially when structuring surfaces, it is not sufficient to consider only two-dimensional roughness parameters. In addition, the scaled profiles and the SEM pictures show that the typical terminology of peaks and grooves is no precise description for the topography of most machined surfaces.

Finally, the investigations show that the coating's interface seems suitable by pre-machining the substrate and generating a patterned homogeneous surface topography. In order to get more information about the impacts of the resulting surface integrity, the fatigue strength will be tested using rotating bending tests. Hereby, the influence of the surface integrity of the substrate in a multilayer workpiece shall be analyzed, and the advantages of the machining surface conditioning for the multilayer substrate shall be addressed.

Author Contributions: Conceptualization, M.T., D.B., M.A., and W.T.; methodology, M.T. and M.A.; formal analysis, M.T. and M.A.; investigation, M.T. and M.A.; resources, D.B. and W.T.; data curation, M.T.; writing-original draft preparation, M.T. and D.B.; writing—review and editing, M.T. and M.A.; visualization, M.T.; supervision, D.B. and W.T.; project administration, M.T. and M.A.; funding acquisition, D.B. and W.T.

Funding: This research, titled with "Improvement of the dynamic strength of thermally sprayed coatings by means of machining surface conditioning", was funded by Deutsche Forschungsgemeinschaft (DFG) - grant number 287021006.

Acknowledgments: The scientific results presented in this manuscript are based on the research project "Improvement of the dynamic strength of thermally sprayed coatings by means of machining surface conditioning", which was funded by Deutsche Forschungsgemeinschaft (DFG) (grant number 287021006).

Conflicts of Interest: The authors declare no conflicts of interest.

\section{References}

1. Mang, T.; Bobzin, K.; Bartels, T. Industrial Tribology: Tribosystems, Friction, Wear and Surface Engineering, Lubrication, 1st ed.; Wiley: Aachen, Germany, 2011; pp. 1-21, 113-136.

2. Goeke, S.; Biermann, D.; Stickel, D.; Stemmer, P.; Fischer, A.; Geenen, K.; Huth, S.; Theisen, W. Enhancing the Surface Integrity of Tribologically Stressed Contacting Surfaces by an Adjusted Surface Topography. Procedia CIRP 2014, 13, 214-218. [CrossRef]

3. Biermann, D.; Abrahams, H.; Goeke, S. Optimization of guide pads for the BTA deep hole drilling of high alloyed steels by microfinishing. Prod. Eng. 2014, 8, 33-40. [CrossRef] 
4. Abrahams, H. Untersuchungen zum Führungsleistenverschleiß und zur Prozessdynamik beim BTA-Tiefbohren austenitischer Stähle. Ph.D. Thesis, Technical University Dortmund, Dortmund, Germany, 2016.

5. Biermann, D.; Goeke, S.; Tillmann, W.; Nebel, J. Improvement of wear resistant thermally sprayed coatings by microfinishing. CIRP Ann. 2013, 62, 559-562. [CrossRef]

6. Tillmann, W.; Hagen, L.; Stangier, D.; Laemmerhirt, I.A.; Biermann, D.; Kersting, P.; Krebs, E. Wear behavior of bio-inspired and technologically structured HVOF sprayed NiCrBSiFe coatings. Surf. Coat. Technol. 2015, 280, 16-26. [CrossRef]

7. Goeke, S. Oberflächenstrukturierung tribologisch beanspruchter Funktionsflächen durch Microfinishen. Ph.D. Thesis, Technical University Dortmund, Dortmund, Germany, 2016.

8. Chivavibul, P.; Watanabe, M.; Kuroda, S.; Shinoda, K. Effects of carbide size and Co content on the microstructure and mechanical properties of HVOF-sprayed WC-Co coatings. Surf. Coat. Technol. 2007, 202, 509-521. [CrossRef]

9. Puchi-Cabrera, E.S.; Staia, M.H.; Lesage, J.; Chicot, D.; La Barbera-Sosa, J.G.; Ochoa-Pérez, E.A. Fatigue performance of a SAE 1045 steel coated with a Colmonoy 88 alloy deposited by HVOF thermal spraying. Surf. Coat. Technol. 2006, 201, 2038-2045. [CrossRef]

10. Costa, M.Y.P.; Venditti, M.L.R.; Voorwald, H.J.C.; Cioffi, M.O.H.; Cruz, T.G. Effect of WC-10\%Co-4\%Cr coating on the Ti-6Al-4V alloy fatigue strength. Mater. Sci. Eng. A 2009, 507, 29-36. [CrossRef]

11. Tillmann, W.; Nebel, J.; Schaak, C.; Biermann, D.; Peuker, A.; Brüggemann, T. Haftung HVOF gespritzter WC-CoCr Schichten auf gefrästen, gestrahlten und geschliffenen Oberflächen. In Proceedings of the 13. Werkstofftechnischen Kolloquium, Chemnitz, Germany, 30 September-1 October 2010; Technische Universtität Chemnitz, Lehrstuhl für Verbundwerkstoffe: Chemnitz, Germany, 2010; pp. 25-36.

12. Adam, P. Fertigungsverfahren von Turboflugtriebwerken. Technik der Turboflugtriebwerke, 1st ed.; Birkhäuser: Basel, Switzerland, 1998; pp. 112-148.

13. Haindl, H. Einfluß der Fertigungsparameter der Haftschicht auf die Lebensdauer keramischer Wärmedämmschichtsysteme. In Werkstoffwissenschaften, 2nd ed.; Utz: München, Germany, 1998; pp. 4-51.

14. Bansal, P.; Shipway, P.H.; Leen, S.B. Residual stresses in high-velocity oxy-fuel thermally sprayed coatings-Modelling the effect of particle velocity and temperature during the spraying process. Acta Mater. 2007, 55, 5089-5101. [CrossRef]

15. Greving, D.; Shadley, J.; Rybicki, E. Effects of coating thickness and residual stresses on the bond strength of ASTM C633-79 thermal spray coating test specimens. J. Therm. Spray Technol. 1994, 3, 371-378. [CrossRef]

16. Matejicek, J.; Sampath, S. In Situ measurement of residual stresses and elastic moduli in thermal sprayed coatings: Part 1: Apparatus and analysis. Acta Mater. 2003, 51, 863-872. [CrossRef]

17. Cutler, R.A.; Virkar, A.V. The effect of binder thickness and residual stresses on the fracture toughness of cemented carbides. J. Mater. Sci. 1985, 20, 3557-3573. [CrossRef]

18. Kovárík, O.; Siegl, J.; Nohava, J.; Chráska, P. Young's modulus and fatigue behavior of plasma-sprayed alumina coatings. J. Therm. Spray Technol. 2005, 14, 231-238. [CrossRef]

19. Pina, J.; Dias, A.; Lebrun, J.L. Mechanical stiffness of thermally sprayed coatings and elastic constants for stress evaluation by X-ray diffraction. Mater. Sci. Eng. A 1999, 267, 130-144. [CrossRef]

20. Sartwell, B.; Legg, K.O.; Schell, J.; Sauer, J.; Natishan, P.; Dull, D.; Falkowski, J.; Bretz, P.; Deveraux, J.; Edwards, C.; et al. Validation of HVOF WC/Co Thermal Spray Coatings as a Replacement for Hard Chrome Plating on Aircraft Landing Gear; Naval Research Laboratory: Washington, DC, USA, 2004; pp. 150-164.

21. Ahmed, R.; Hadfield, M. Mechanisms of fatigue failure in thermal spray coatings. J. Therm. Spray Technol. 2002, 11, 333-349. [CrossRef]

22. Clyne, T.W.; Gill, S.C. Residual Stresses in Thermal Spray Coatings and Their Effect on Interfacial Adhesion: A Review of Recent Work. J. Therm. Spray Technol. 1996, 5, 401-418. [CrossRef]

23. López, D.; Candel, A.; Gadow, R. Herstellung von tribologischen Schutzschichten auf Zylinderlaufflächen durch das HVOF-Verfahren. Materialwissenschaft und Werkstofftechnik 2006, 37, 312-317. [CrossRef]

24. DIN 8589-14. Fertigungsverfahren Spanen-Teil 14: Honen-Einordnung, Unterteilung, Begriffe; National Standard, DIN German Institute for Standardization: Berlin, Germany, 2003.

25. Schibisch, D.M.; Friedrich, U. Superfinish-Technologie: Feinste Oberflächen für höchste Präzision, 2nd ed.; Verlag Moderne Industrie: Landsberg/Lech, Germany, 2005; pp. 1-70.

26. Hashimoto, F.; Yamaguchi, H.; Krajnik, P.; Wegener, K.; Chaudhari, R.; Hoffmeister, H.W.; Kuster, F. Abrasive fine-finishing technology. CIRP Ann. Manuf. Technol. 2016, 65, 597-620. [CrossRef] 
27. Serpin, K.; Mezghani, S.; El Mansori, M. Wear study of structured coated belts in advanced abrasive belt finishing. Surf. Coat. Technol. 2015, 284, 365-376. [CrossRef]

28. Khellouki, A.B.; Rech, J.; Zahouani, H. Micro-scale investigation on belt finishing cutting mechanisms by scratch tests. Wear 2013, 308, 17-28. [CrossRef]

29. Martin, K.; Yegenoglu, K. HSG-Technologie: Handbuch zur praktischen Anwendung; Firma Guehring Automation GmbH: Stetten a.k.M.-Frohnstetten, Germany, 1992.

30. Martin, K. Der Werkstoffabtragvorgang beim Feinbearbeitungsverfahren Honen. Maschinenmarkt Würzburg 1976, 60, 1074-1078.

31. Zum Gahr, K.H. Wear by hard particles. Tribol. Int. 1998, 31, 587-596. [CrossRef]

32. Tilger, M.; Siebrecht, T.; Biermann, D. Fundamental Investigations of Honing Processes Related to the Material Removal Mechanisms. In Proceedings of the 7. WGP-Jahreskongress, Aachen, Germany, 5-6 October 2017; Schmitt, R.H., Schuh, G., Eds.; Apprimus Verlag: Aachen, Germany; pp. 121-128.

33. DIN EN ISO 4287. Geometrical Product Specifications (GPS)—Surface Texture: Profile Method_Terms, Definitions and Surface Texture Parameters; International Standard; DIN German Institute for Standardization: Berlin, Germany, 2010.

34. DIN EN ISO 13565-2. Geometrical Product Specifications (GPS)—Surface Texture: Profile Method-Surfaces having Stratified Functional Properties; International Standard; DIN German Institute for Standardization: Berlin, Germany, 1996.

35. Noyan, I.C.; Cohen, J.B. Residual Stress-Measurement by Diffraction and Interpretation, 1st ed.; Springer: New York, NY, USA, 1987; pp. 47-229.

36. Hauk, V. Structural and Residual Stress Analysis by Nondestructive Methods, 1st ed.; Elsevier Science B.V.: Amsterdam, The Netherlands, 1997; pp. 17-494.

(C) 2019 by the authors. Licensee MDPI, Basel, Switzerland. This article is an open access article distributed under the terms and conditions of the Creative Commons Attribution (CC BY) license (http://creativecommons.org/licenses/by/4.0/). 